\title{
Research on Marketization of New energy consumption
}

\author{
Zhuhan Long ${ }^{1,}{ }^{,}{ }^{*}$, Yuqing Wang ${ }^{1}$, Yan Yang ${ }^{1}$, Lirong $\mathrm{Xie}^{2}$, Xin $\mathrm{Qi}^{3}$, Liu Wei ${ }^{1}$, \\ Ming Zeng ${ }^{1}$ \\ ${ }^{1}$ School of Economics and Management, North China Electric Power University, Beijing, China \\ ${ }^{2}$ Nari Technology Development Limited Company, Nanjing, China \\ ${ }^{3}$ State Grid Ningxia Electric Power Company, Yinchuan, China \\ a Corresponding author e-mail: 532300376@qq.com
}

Keywords: new energy consumption; market stage; industry development characteristics; market characteristics; market mechanism.

\begin{abstract}
In recent years, the contradiction between China's new energy consumption has become increasingly prominent. When the installed capacity is increasing year by year, the abandonment rate of abandoned the wind and abandoned light is high, and how to promote the new energy consumption through market means is the urgent problem to be solved. In this paper, the new energy consumption market is divided into three stages, namely, the new energy power generation priority stage, the new energy power generation priority trading stage and the complete competitive market stage; then, it needs to elaborate each stage of the industry development characteristics, market characteristics and the market mechanism.
\end{abstract}

\section{Introduction}

In recent years, China's new energy consumption has become increasingly prominent contradiction, when the new energy installed capacity is increasing year by year, the phenomenon of abandoned the wind abandoned light is increasingly serious[1-2]. By the end of 2016, China's wind power cumulative grid installed capacity is 149 million $\mathrm{kW}$, accounting for $9 \%$ of the total installed capacity of power generation; total cumulative generating capacity is 241 billion $\mathrm{kWh}$; photovoltaic cumulative installed capacity is 77.42 million $\mathrm{kW}$, including the cumulative installed capacity of photovoltaic power plant is 67.1 million $\mathrm{kW}$, accounting for about $87 \%$; distributed cumulative installed capacity is 10.32 million $\mathrm{kW}$, accounting for about $13 \%$; solar energy cumulative generating capacity is 66.2 billion $\mathrm{kWh}$. At the same time, the number of abandoned wind power in 2016 reached a record high of 49.7 billion $\mathrm{kWh}$, an increase of 15.8 billion $\mathrm{kWh}$ compared with 2015 , an average of $20.6 \%$ of the abandonment rate, and the number of abandoned solar power is 7.04 billion $\mathrm{kWh}$, 2.93 billion $\mathrm{kWh}$ higher than 2015,an average rejection rate of $10.6 \%$.

The Chinese government has made a commitment to the international community to increase the proportion of non-fossil fuels to $20 \%$ of the energy consumption in 2030 , and many scholars have studied the issue of new energy consumption[3-4]. Literature [5] based on the analysis of the new round of power market reform, it is needed to research the foreign power market how to promote the experience of new energy consumption in order to sum up the study of its problems and solutions ,by doing this we can propose market construction suggest to promote China's new energy consumption. In order to solve the problems of new energy development and new energy dispatching in Ningxia, literature[6] analyzes the important role of new energy acceptance capability in new energy dispatching, and then puts forward a new method for assessing the main new energy access area and the grid day ahead new energy acceptance method. On the basis of summarizing the current situation of new energy consumption in China, literature [7] analyzes the mechanism of generating new energy consumption problem, and points out the key factors that affect the problem of the new energy of abandoned the wind and abandoned light .measures are systematically put forward to solve the problem of new energy consumption in China. This paper first divides the new energy consumption 
market into three stages. Then, the development characteristics, market characteristics and market mechanism of each stage are expounded.

\section{New Energy Consumption Market Segmentation}

According to the characteristics of the new energy market, from the perspective of administrative means and market means, the new energy consumption market stage can be divided into new energy power generation priority given to the stage, the new energy power generation priority trading stage and the complete competitive market stage.

From the new energy power generation priority stage to the new energy power generation priority trading stage, and then to the final stage of complete competitive market, the degree of the new energy industry marketization gradually increased, the state's policy support and financial support and other administrative means are gradual reduced.

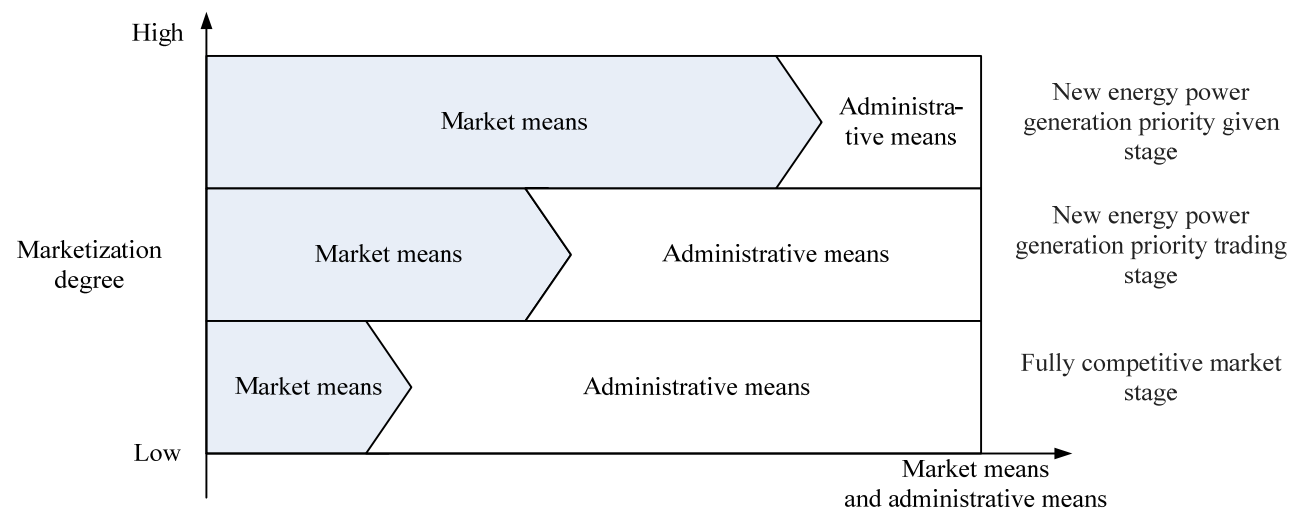

Fig 1. Different stages of the new energy industry marketization

\section{The Characteristics of the Various Stages of The Market}

\subsection{New Energy Power Generation Priority Given Stage}

\subsubsection{Industry Development Characteristics}

In the new energy power generation priority given to the stage, the new energy power generation capacity increased rapidly. However, because of its own inter-sexual, volatility and transportation channels and other reasons such as power grid construction are not perfect. At this stage, the situation of abandoned wind and abandoned light is serious, and the new energy consumption is difficult.

The new energy have advantages in clean, renewable and so on, the state at this stage will give strong support to the policy and the relevant financial subsidies to support the rapid development of new energy industry, the overall capacity of new energy capacity growth was significantly higher than the national total installed capacity of generating units speed, power generation gradually increased the proportion. Moreover, the new energy power generation costs will continue to decline, and gradually close to the cost of fossil fuel power generation, the corresponding price began to adjust. In short, the new energy industry through policy support, capital investment, technological progress and scale production will achieve significant improvements in cost structure.

\subsubsection{Market Characteristics}

New energy power generation priority given to the stage mainly undertakes the long-term electricity transactions, that is to say, the main body of selling electricity and purchase of electricity are in accordance with the provisions of the contract transactions. Through the means of bilateral transaction, the main body of electricity buyer purchases electricity from the main body of electricity seller, and in accordance with the provisions of the contract to pay the cost, sales of the main body in accordance with the contract requirements within the prescribed time to provide the corresponding power. Electricity transactions can also be divided into provincial electricity transactions, interprovincial electricity transactions and interregional electricity transactions. The main body of electricity transaction, in addition to the main body of electricity and the purchase of the main body, include power grid trading center, power grid dispatch center and other non-transactional main body. 
The grid dispatching organization dispatches the transaction power according to the physical condition of the grid and the actual demand of the user electricity.

\subsubsection{Market Mechanism}

In the new energy power generation priority given to the stage, in order to promote new energy consumption, we should be based on different time periods and spatial distance on a variety of energy base output power of different impact characteristics, and set the new energy power generation priority. Through the reference to renewable energy quota system theory, we can design new energy power generation priority giving mechanism.

The new energy power generation priority requires implementing the new energy protection of the power generation to protect the new energy projects reasonable income of the basic utilization of the number of hours. The newly revised "Renewable Energy Law" clearly stipulates that the state will implement the full purchase of renewable energy power purchase system, power grid enterprises should be in accordance with the development and utilization of renewable energy planning and construction, according to the law to obtain administrative license or submitted for the record of renewable energy power generation enterprises signed a grid agreement, the full acquisition of its grid coverage within the grid and meet the technical standards of renewable energy grid-connected power generation project power. In a series of power system reform supporting documents, they clear the establishment of priority power generation system requirements, around the arrangements for the annual power generation plan, to fully reserve the power generation space, in the annual construction scale of the new project put into production Year to determine the number of years to protect the use of affordable. Among them, wind power, solar power, biomass power generation, waste heat and residual pressure power generation are in accordance with the conditions of resources in full power generation. However, there are certain obstacles to the conception of the priority of new energy power generation, which includes both the technical requirements of the grid and the coordination of the peak and the relationship between the areas, and some key issues. There is no specific implementation path, or the existing rules are too vague.

\subsection{New Energy Power Generation Priority Trading Stage}

\subsubsection{Industry Development Characteristics}

The core issue of new energy development is the cost of national new energy industry in the development process will try to adopt new technologies, strengthen financing, change the mode of operation and other methods to further reduce costs. The use of traditional fuel power generation is prone to pollution, such as increased carbon emissions, which will face more and more restrictions and increase the cost of the problem, which makes new energy power generation more market competitiveness. It is expected that with the technological progress and scale, in the new energy power generation priority trading stage, including wind power and solar energy, including new energy power generation costs will continue to decline, the new energy industry will further increase the degree of marketization, the scale will be further expanded.

\subsubsection{Market Characteristics}

In the new energy power generation priority trading stage in addition to long-term electricity transactions, but also to carry out a few days ago trading and power generation transactions. In the recent transaction, the grid as the market transaction information to master the most comprehensive institutions, it should be used as a market trading and scheduling center, coordination of different power generation enterprise power generation scheduling; Similarly, power generation enterprises need to actively cooperate with the power grid scheduling, coordination in the grid business, Through the centralized match or focus on free bidding mechanism to complete the new energy power generation priority transactions or new energy and electricity transactions. The power generation priority transaction is the market way to achieve the power generation between the generating units paid and transferee alternative transactions, generally within the scope of provincial power grids. To carry out power generation priority transactions should be considered with the power market construction work, into the market construction planning, and other types of transactions to achieve the optimal coordination and convergence. 


\subsubsection{Market Mechanism}

With the gradual expansion of the scale of renewable energy power generation industry and the continuous improvement of its own development capacity, the support and incentive mechanism of new energy power generation must also be commercialized, forming a system of government policy guidance and green electricity market mechanism. Therefore, we should introduce the auxiliary system of quota system - the theory of renewable energy certificate system, and build a market-based new energy priority trading system.

The Renewable Energy Certificate-REC system, also known as the Green Electricity Certificate System, is a policy tool based on the Renewable Energy Quota System. The implementation of the quota system needs to be run in conjunction with the Renewable Energy Certificate Trading Market.

Renewable energy certificate is a means to achieve the quota system, but also to achieve a quota system to prove. The power companies that bear the quota obligations can create renewable energy certificates by producing renewable energy sources themselves, or from other renewable energy power producers, by purchasing long-term contracts to purchase additional renewable energy certificate.

\subsection{Fully Competitive Market Stage}

\subsubsection{Industry Development Characteristics}

Into the fully competitive market stage, the new energy will participate in market bidding, government subsidies and support policies will gradually out of this time, the new energy power generation and traditional power generation costs basically flat or lower, and then in the power grid has a certain Advantage.

\subsubsection{Market Characteristics}

In the fully competitive market stage, the cost of new energy power generation has been competitive, in addition to the existing long-term electricity transactions, a few days before the market transactions and power generation priority transactions, but also the introduction of real-time trading of electricity spot market and auxiliary services market. New energy directly involved in interprovincial market competition transactions. Open days of the market, to provide a flexible transaction reporting and forecasting update mechanism to achieve market-oriented resources to optimize the allocation. At this stage, the ancillary services transactions, including spare, FM and reactive, etc., the subject of the subject and the source will continue to enrich the transaction, requiring the main body of electricity or power purchase by the power grid dispatch center signed a bilateral contract to get their required Ancillary services.

\subsubsection{Market Mechanism}

In the fully competitive market stage, we can continue to strengthen the power grid construction, especially inter-provincial transmission line construction is to promote the elimination of new energy necessary means, unified power market must have a strong cross-regional power grid as a support. Power transmission is inseparable from the grid, which in the market transactions have a key role. Power grid construction is backward, power grid structure is weak, are the main obstacles to the reform of the electricity market. Only in the construction of a strong power grid, especially across the region, long-distance and large-capacity transmission lines, in order to better achieve nationwide cross-provincial power transactions and optimal allocation of resources to ensure energy supply security.

In the fully competitive market phase, new energy power generation is directly involved in the electricity market and is subject to a balance of power system, similar to conventional power supplies, which also treats new energy and conventional power supplies as commodities in the market without any additional subsidies and benefits. Eliminating the "special" of new energy power generation, return to its "universal" as energy products, is conducive to inspire new energy power generation according to market supply and demand situation to adjust their own output, reduce system operating pressure, and create a fair and equitable market environment. 


\begin{tabular}{|c|c|c|c|}
\hline & $\begin{array}{l}\text { New energy power generation } \\
\text { priority given stage }\end{array}$ & $\begin{array}{c}\text { New energy power } \\
\text { generation priority trading } \\
\text { stage }\end{array}$ & $\begin{array}{l}\text { Fully competitive market } \\
\text { stage }\end{array}$ \\
\hline $\begin{array}{l}\text { Market } \\
\text { subject }\end{array}$ & $\begin{array}{l}\text { New energy power } \\
\text { generation enterprise; } \\
\text { Power user; } \\
\text { Power grid enterprise; } \\
\text { Government }\end{array}$ & $\begin{array}{c}\text { New energy power } \\
\text { generation enterprise; } \\
\text { Traditional thermal power } \\
\text { enterprise; } \\
\text { Power user; } \\
\text { Power grid enterprise } \\
\end{array}$ & $\begin{array}{l}\text { New energy power } \\
\text { generation enterprise; } \\
\text { Power user; } \\
\text { Power grid enterprise }\end{array}$ \\
\hline $\begin{array}{l}\text { Market } \\
\text { category }\end{array}$ & $\begin{array}{l}\text { Medium and long term } \\
\text { trading market }\end{array}$ & $\begin{array}{c}\text { Medium and long term } \\
\text { trading market } \\
\text { The day-ahead trading } \\
\text { market } \\
\text { Power generation priority } \\
\text { market }\end{array}$ & $\begin{array}{l}\text { Medium and long term } \\
\text { trading market } \\
\text { The day-ahead trading } \\
\text { market } \\
\text { Real-time trading market } \\
\text { Power generation priority } \\
\text { market } \\
\text { Ancillary services market }\end{array}$ \\
\hline $\begin{array}{l}\text { Transaction } \\
\text { variety }\end{array}$ & Electricity power trading & $\begin{array}{l}\text { Electricity power trading; } \\
\text { Generation priority } \\
\text { transaction }\end{array}$ & $\begin{array}{l}\text { Electricity power trading; } \\
\text { Generation priority } \\
\text { transaction; } \\
\text { Ancillary services trading }\end{array}$ \\
\hline $\begin{array}{l}\text { Trading } \\
\text { mechanism }\end{array}$ & $\begin{array}{l}\text { - Total design of new } \\
\text { energy generation priority; } \\
\text { - Allocation of power } \\
\text { generation priorities; } \\
\text { - Info Diffusion; } \\
\text { - New energy trading first; } \\
\text { - Traditional thermal power } \\
\text { enterprise transaction; } \\
\text { - Dispatching adjustment }\end{array}$ & $\begin{array}{l}\text { - Priority giving; } \\
\text { - Priority transaction } \\
\text { (Market organization、 } \\
\text { Trading rules、 } \\
\text { Transaction price、 } \\
\text { Trading system); } \\
\text { - Electricity power trading }\end{array}$ & $\begin{array}{l}\text { - Population model } \\
\text { determination; } \\
\text { - Generation side bidding } \\
\text { mode; } \\
\text { - Inter-provincial trading } \\
\text { price mechanism; } \\
\text { - Balance mechanism }\end{array}$ \\
\hline
\end{tabular}

Figure 2. Three-phase comparison chart

\section{Conclusion}

With China's access to the control of air pollution, promote energy transformation and upgrading, to achieve the key stage of green development, power to the direction of energy policy has been relatively clear, for the consumption of new energy has a strong will, is now from policy to Marketoriented to promote the new energy consumption of the transition phase, that is, the new energy power generation priority to stage the transition to the new energy power generation priority trading stage. With the further improvement of the degree of marketization, the relevant market mechanism can be improved. It may be gradually to the stage of perfect competition market development, so as to promote the adoption of market-oriented means of new energy consumption.

\section{Acknowledgments}

This work was financially supported by the Science and Technology Project of SGCC (SGNX0000DKJS1600128).

\section{References}

[1]. Zhang Boming, Wu Wencheng, Zheng Taiyi, et al. Design of multi-time scale coordinated active scheduling system for large-scale wind power generation [J]. Automation of Electric Power Systems, 2011, 35 (1): 1-6.

[2]. Zhang Ning, Zhou Tianrui, Duan Changgang, et al. Influence of large-scale wind farm access on power system peaking [J]. Power System Technology, 2010,34 (1): 152-158.

[3]. PEI Zheyi, FAN Gaofeng. Research on wind power operation and tile problems in China [J]. Electric Power, 2014, 47 (4): 1-4.

[4]. PEI Zheyi, Wang Caixia, He Qing, et al. Analysis and Suggestions on Renewable Energy Integration Problems in China [J]. Electric Power, 2016, 49 (11): 1-7.

[5]. Wang Caixia, Li Qionghui. Foreign energy consumption market mechanism and enlightenment to China [J]. Foreign Energy, 2016, 36 (8): 33-37. 
[6]. Han Hongwei. New energy acceptance capacity of the assessment method and application [J]. Ningxia Electric Power, 2014 (6): 43-47.

[7]. Shu Yin Biao, Zhang Zhigang, Guo Jianbo, et al. Study on the key factors of new energy consumption and the solution measures [J]. Proceeding of the CSEE, 2017,37 (1): 1-8. 